\title{
RESEARCH
}

Open Access

\section{Predictive factors of epilepsy outcome in a sample of Egyptian pre-elderly and elderly population}

Steven Emil Gerges ${ }^{*}$ (D), Mahmoud Hemeda El Rakawy, Naglaa Mohammed El Khayat, Yousry Abo Elnaga Abdelhamid, Ahmed Mohammed Hazzou, Hossam Mohammed Shokri and Mona Mokthar Wahid El din

\begin{abstract}
Background: Elderly people with epilepsy are large, but neglected group. Data on the predictive factors for recurrent seizures in the elderly population are inconclusive or are not known for the majority of patients. This is especially true for the Egyptian population as no specific study was concluded to address this issue before.

Objectives: The aim of this study was to detect the predictive factors of epilepsy outcome in a sample of Egyptian aged population.

Materials and methods: A total of 100 patients aged 50 years or older with epilepsy diagnosed according to International League Against Epilepsy (ILAE) latest definition were included in the study and followed up for 6 months as regards seizure control. All participants were prospectively evaluated for epidemiological, clinical, radiological, electrodiagnostic, and laboratory data.
\end{abstract}

Results: The outcome was statistically significant affected in relation to absence of medical comorbidities $(P=$ 0.037), seizure etiology $(P=0.007)$, history of status epilepticus $(P<0.001)$, MRI brain findings $(P=0.005)$, EEG changes $(P<0.001)$, Ca $(P=0.01)$, and Mg level $(P=0.046)$.

Conclusion: We conclude that aged Egyptian epileptic population with no medical comorbidities, normal MRI brain, or normal EEG can be predicted to have good outcome of their epilepsy while patients with post stroke epilepsy, abnormal MRI brain, and abnormal EEG, with low serum Ca or Mg level can be predicted to have poor outcome.

Keywords: Egyptian, Elderly, Epilepsy, Predictive factors

\section{Introduction}

The overall age-specific incidence of epilepsy is bimodal, with a peak in the newborn and a more pronounced peak in those aged over 60 years [1].

Despite the growing prevalence of elderly epilepsy patients, evidence from double-blind randomized controlled trials of this age group still remain inadequate. It is not surprising that elderly individuals are easily excluded from clinical trials due to underlying

\footnotetext{
*Correspondence: stevnemil7@gmail.com

Faculty of Medicine, Ain Shams University, Cairo, Egypt
}

comorbidities, polypharmacy or relatively short life expectancy [2].

Results from studies of prognosis of epilepsy are often conflicting. Some of the variability can be explained on the basis of differences in populations and methodologies. Although there are few published results on epilepsy prognosis in the elderly, the outlook on antiepileptic drugs (AEDs) is generally considered good, perhaps better than in younger patients [3].

It is important to improve understanding of possible prognostic factors and the many conditions associated with epilepsy in the elderly. Age-related changes in renal 
and hepatic functions, comorbidities and comedications may contribute to facilitating the occurrence of status epilepticus and the AED treatment should be established taking these issues into account [4].

Data on the risk factors for recurrent seizures in the elderly population are inconclusive or are not known for the majority of patients [5]; this is especially true for Egyptian aged population where no specific study addressed this issue before to the best of our knowledge.

In the present study, we assess the predictive factors of epilepsy outcome in this population.

\section{Methods}

A group of 100 patients with epilepsy aged 50 years old or older from the outpatient epilepsy clinic and neurology department of our institute chosen consecutively were included in this study. The study was performed between march 2019 and June 2020. The procedures followed were in accordance with the ethical standards of the responsible committee on human experimentation and with the principles of Helsinki declaration [6]. Written informed consent was obtained from all participants, and ethical committee permission from our institute was obtained before starting our work. Inclusion criteria were as follows: patients aged 50 years old or older of both sexes with any type of epilepsy as defined by the international league against epilepsy (ILAE) [7] with any age of seizure onset. Patients with provoked seizures (metabolic, toxic, structural, infectious, or inflammatory) were excluded from the study.

All the participants were subjected to the following: clinical evaluation including: general medical history and examination, full neurological history and examination, full details about seizures including (proposed seizure etiology, family history of epilepsy, age of seizure onset, monthly seizure frequency, seizure precipitants, history of status epilepticus, anti-epileptic drugs used), routine surface EEG using the 10-20 International Electrode System (Natus, Nicolet EEG n32, USA), MRI brain (1.5 MR scanner Achieva and Ingenia, Philips medical system, Eindhoven, Netherlands) using T1, T2 (axial and coronal cuts) and FLAIR sequences in all patients with or without contrast enhancement individualized according to each patient condition, laboratory tests including complete blood count, electrolytes $(\mathrm{Na}, \mathrm{K}, \mathrm{Ca}, \mathrm{Mg}$ ) level, random blood glucose level, liver enzymes, and kidney function tests.

The patients received anti-epileptic medications or their medications were adjusted if needed individualized according to each patient condition following the standard protocols for treatment of epilepsy. All patients were followed up for 6 months to detect the outcome of their epilepsy as regard seizure frequency: Absence of seizures or reduction in its frequency by at least $50 \%$ was considered as a good prognosis, less than $50 \%$ reduction in seizures frequency was considered as a poor prognosis [8]. We used the IBM SPSS software package version 20.0 for data analysis. (Armonk, NY: IBM Corp.). Qualitative data was described using numbers and percentage points. Quantitative data was described using a range (minimum and maximum), a mean, or a standard deviation, a median, and an interquartile range (IQR). Chisquare test was used for categorical variables, to compare between different categories. Student's $t$ test was used for normally distributed quantitative variables, to compare between two studied categories, while MannWhitney test was used for non-normally distributed quantitative variables. $P<0.05$ was considered statistically significant. Chi-square post hoc test was used to detect the contribution of the different variables in the outcome. Adjusted residual $\geq 1.96$ or $\leq-1.96$ was considered significant.

\section{Results}

A total of 100 participants, including 56 males and 44 females were included in current study. All patients were of Egyptian nationality. The participants' demographic and clinical data are given in Table 1.

Other clinical, radiological and EEG data are given in Table 2.

Laboratory data are given in Table 3.

The patients were followed up for 6 months. The seizure frequency at beginning of the study ranged from 0.08 to 30 seizure/month with the median frequency was 2 seizures/month. The seizure frequency after 6 months ranged from 0.04 to 30 seizure/month with the median frequency was 0.5 seizure/month. The seizure frequency was significantly decreased at follow-up $(P<.001)$. The

Table 1 Descriptive results and clinical characteristics of the studied subjects

\begin{tabular}{|c|c|c|}
\hline \multicolumn{2}{|l|}{ Variables } & $n=100$ \\
\hline \multicolumn{2}{|l|}{ Male (\%) } & $56 \%$ \\
\hline \multicolumn{2}{|l|}{ Age (mean), years } & $55.42 \pm 6.28$ \\
\hline \multicolumn{2}{|c|}{ Age of epilepsy onset (mean), years } & $35.13 \pm 18.16$ \\
\hline \multicolumn{2}{|c|}{ Positive family history of epilepsy (\%) } & $26 \%$ \\
\hline \multicolumn{2}{|c|}{ No medical comorbidities (\%) } & $62 \%$ \\
\hline \multicolumn{2}{|l|}{ Hypertension (\%) } & $28 \%$ \\
\hline \multicolumn{2}{|l|}{ Diabetes (\%) } & $12 \%$ \\
\hline \multicolumn{2}{|c|}{ Ischemic heart disease (\%) } & $6 \%$ \\
\hline \multirow[t]{5}{*}{ Seizure etiology (\%) } & Unspecified etiology & $39 \%$ \\
\hline & Post stroke epilepsy & $23 \%$ \\
\hline & Post traumatic epilepsy & $12 \%$ \\
\hline & Proposed genetic epilepsy & $18 \%$ \\
\hline & Other etiologies & $8 \%$ \\
\hline
\end{tabular}


Table 2 Descriptive results and clinical characteristics of the studied subjects (continued)

\begin{tabular}{lll}
\hline Variables & & $\boldsymbol{n}=\mathbf{1 0 0}$ \\
\hline Status epilepticus (\%) & & $16 \%$ \\
Seizure precipitants (\%) & No precipitants & $35 \%$ \\
& Stress & $31 \%$ \\
& Sleep & $12 \%$ \\
& Sleep deprivation & $13 \%$ \\
Anti-epileptic drugs (\%) & Carbamazepine & $43 \%$ \\
& Valproate & $39 \%$ \\
& Phenytoin & $14 \%$ \\
MRI brain findings (\%) & Levetiracetam & $33 \%$ \\
& Normal & $56 \%$ \\
& Encephalomalacia & $30 \%$ \\
EEG changes (\%) & Temporal atrophy & $7 \%$ \\
& Normal & $55 \%$ \\
& Focal changes & $37 \%$ \\
& Generalized changes & $10 \%$ \\
\hline
\end{tabular}

AED anti-epileptic drug, $M R I$ magnetic resonance imaging,

EEG electroencephalography

outcome was considered good (absence of seizures or reduction in its frequency by at least $50 \%$ ) at 77 patients and considered poor (less than $50 \%$ reduction in seizures frequency) at 23 patients.

In order to investigate the factors related to outcome among epilepsy patients, different parameters were compared between patients with good and poor outcome. These data are given in Table 4.

Other parameters are given in Table 5 .

Chi-square post hoc tests are given in Table 6.

Laboratory parameters are given in Table 7.

Table 3 Laboratory data of the studied subjects

\begin{tabular}{ll}
\hline Variables & $n=100$ \\
\hline Hemoglobin (mean) gm/dl & $12.47 \pm 1.70$ \\
Platelets (mean) × 109/L & $328.23 \pm 92.41$ \\
Na (mean) $\mathbf{~ m E q / L ~}$ & $139.60 \pm 3.19$ \\
K (mean) mEq/L & $4.06 \pm 0.40$ \\
Ca (mean) mEq/L & $9.83 \pm 0.79$ \\
Mg (mean) mEq/L & $2.02 \pm 0.16$ \\
ALT (mean) IU/L & $25.04 \pm 21.21$ \\
AST (mean) IU/L & $29.11 \pm 35.40$ \\
Random blood sugar (mean) mg/dl & $127.39 \pm 44.88$ \\
Creatinine (mean) mg/dl & $0.94 \pm 0.28$ \\
BUN (mean) mg/dl & $34.32 \pm 12.89$ \\
\hline
\end{tabular}

Na sodium, $K$ potassium, $C a$ calcium, $M g$ magnesium, ALT alanine transferase, AST aspartate transferase, BUN blood urea nitrogen

\section{Discussion}

Data on the predictive factors for recurrent seizures in the elderly population are inconclusive or are not known for the majority of patients. This is especially true for the Egyptian population as no specific study was concluded to address this issue before to the best of our knowledge. This encouraged the design of this study in order to detect such factors and to correlate the results with various epidemiological, clinical, radiological, electrodiagnostic, and laboratory data.

In this study, the seizure frequency was significantly decreased after 6 months of follow-up. This may reflects the fact that epilepsy in elderly is not only easily controlled by AEDs [2] but also refers to the problem of poor adherence to the treatment by a large section of Egyptian elderly population either because of noncompliance or wrong prescription of AEDs or nonaffordability with the medications price.

In this study, there was no significant relationship between gender, age, or age of onset and outcome. This is consistent with other studies as regard gender [9-12]. On the other hand, there was a report that hormone effect especially progesterone can account for difference in promoting and enhancing repair after traumatic brain injury and stroke which may enhance epilepsy outcome [13]. Multivariate analyses of prognostic factors have found no independent correlation of age at onset with prognosis. It is likely that any differences are a reflection of the epilepsy syndromes that are prevalent among the various age groups [14]. Analysis of the Glasgow cohort of newly diagnosed epilepsy suggested that outcomes were generally better in patients aged over 65 years at the onset of epilepsy [3]. Possible explanations include lack the neuronal plasticity needed for the development of pharmacoresistance and reduced likelihood of genetic factors adversely affecting prognosis.

In this study, there was no significant relationship between family history of epilepsy and the outcome. Studies in children and adults have reported an association between family history of epilepsy and poorer prognosis [15]. In generalized syndromes, this could be related to the underlying genetic mechanisms underpinning the epilepsy, which might also be responsible for determining drug response [16]. The role of genetic factors in focal epilepsies is less clear. Genetically determined malformations of cortical development may play a role [17] as may pharmacogenetic traits that run in families [18]. In this study, there was a statistically significant relationship between absence of medical comorbidities and good outcome of epilepsy but analysis of the relationship between specific illnesses such as hypertension, DM, ischemic heart disease, and outcome found no significant relationship. This may be due to the relative 
Table 4 Clinical predictors of outcome in the studied subjects

\begin{tabular}{|c|c|c|c|c|}
\hline \multicolumn{2}{|l|}{ Variables } & Good outcome & Poor outcome & $P$ value \\
\hline \multicolumn{2}{|l|}{ Male (\%) } & $55.84 \%$ & $56.52 \%$ & 0.954 \\
\hline \multicolumn{2}{|l|}{ Age (mean), years } & $55.31 \pm 6.38$ & $54.83 \pm 6.24$ & 0.748 \\
\hline \multicolumn{2}{|c|}{ Age of epilepsy onset (mean), years } & $34.13 \pm 18.14$ & $38.48 \pm 18.21$ & 0.316 \\
\hline \multicolumn{2}{|c|}{ Positive family history of epilepsy (\%) } & $27.3 \%$ & $21.7 \%$ & 0.595 \\
\hline \multicolumn{2}{|c|}{ Absence of medical comorbidities (\%) } & $70.13 \%$ & $34.78 \%$ & $0.037^{*}$ \\
\hline \multicolumn{2}{|l|}{ Hypertension (\%) } & $24.68 \%$ & $39.13 \%$ & 0.175 \\
\hline \multicolumn{2}{|l|}{ Diabetes (\%) } & $10.39 \%$ & 17.39 & 0.365 \\
\hline \multicolumn{2}{|c|}{ Ischemic heart disease (\%) } & $5.19 \%$ & $8.70 \%$ & 0.535 \\
\hline \multirow[t]{4}{*}{ Seizure etiology (\%) } & Unspecific etiology & $44.16 \%$ & $21.74 \%$ & \multirow[t]{4}{*}{$0.007^{*}$} \\
\hline & Post stroke epilepsy & $15.58 \%$ & $47.83 \%$ & \\
\hline & Post traumatic epilepsy & $12.99 \%$ & $8.70 \%$ & \\
\hline & Proposed genetic epilepsy & $20.78 \%$ & $8.70 \%$ & \\
\hline
\end{tabular}

small number of cases with those illnesses. A study by Assis and colleagues also found association of a higher number of comorbidities with early seizure recurrence; thus, they hypothesized that patient multimorbidity is a risk factor for early seizure recurrence [5].

In this study, there was a significant relationship between post stroke epilepsy, either infarction or hemorrhage, and poor outcome. The presence of structural brain lesion was repeatedly reported as a risk factor for seizure recurrence in elderly [19-23]. The changed structure and function of the central nervous system (CNS) in symptomatic epilepsy led to hyper-excitability as the main cause of epilepsy [24]. Brain lesions resulted in neuronal death and reactive gliosis. One of the mechanisms of drug-resistant epilepsy (DRE) is the "transporter hypothesis", and the structural abnormalities damage the capillary endothelial cells that constitute the blood-brain barrier, leading to the overexpression of efflux transports and drug resistance [25].

In this study, history of status epilepticus was significantly associated with poor outcome of epilepsy. This was also reported in many studies $[11,19,26]$. Between 10 and $30 \%$ of people who have status epilepticus die within 30 days [27]. The great majority of these people have an underlying brain condition causing their status seizure such as brain tumor, brain infection, brain trauma, or stroke. However, people with diagnosis of epilepsy who have a status epilepticus also have an increased risk of death if their condition is not stabilized

Table 5 Clinical predictors of outcome in the studied subjects (continued)

\begin{tabular}{|c|c|c|c|c|}
\hline Variables & & Good outcome & Poor outcome & $P$ value \\
\hline Status epilepticus (\%) & & $5.19 \%$ & $52.17 \%$ & $<0.001^{*}$ \\
\hline \multirow[t]{4}{*}{ Seizure precipitants (\%) } & No precipitants & $36.36 \%$ & $30.43 \%$ & 0.103 \\
\hline & Stress & $33.77 \%$ & $21.74 \%$ & \\
\hline & Sleep & $12.99 \%$ & $8.70 \%$ & \\
\hline & Sleep deprivation & $10.39 \%$ & $21.74 \%$ & \\
\hline \multirow[t]{4}{*}{ Anti-epileptic drugs (\%) } & Carbamazepine & $42.86 \%$ & $43.48 \%$ & 0.958 \\
\hline & Valproate & $41.56 \%$ & $30.43 \%$ & 0.337 \\
\hline & Phenytoin & $11.69 \%$ & $21.74 \%$ & 0.223 \\
\hline & Levetiracetam & $28.57 \%$ & $47.83 \%$ & 0.085 \\
\hline \multirow[t]{3}{*}{ MRI brain findings (\%) } & Normal & $64.94 \%$ & $26.09 \%$ & $0.005^{*}$ \\
\hline & Encephalomalacia & $24.68 \%$ & $47.83 \%$ & \\
\hline & Temporal atrophy & $3.90 \%$ & $17.39 \%$ & \\
\hline \multirow[t]{3}{*}{ EEG changes (\%) } & Normal & $66.23 \%$ & $17.39 \%$ & $<0.001^{*}$ \\
\hline & Focal changes & $29.87 \%$ & $60.87 \%$ & \\
\hline & Generalized changes & $5.19 \%$ & $26.09 \%$ & \\
\hline
\end{tabular}


Table 6 Chi-square post hoc test for selected parameters

\begin{tabular}{llll}
\hline Variables & & Adjusted resisual of good outcome & Adjusted residual of poor outcome \\
\hline Seizure etiology & Unspecific etiology & 1.93 & -1.93 \\
& Post stroke epilepsy & 2.20 & -2.20 \\
& Post traumatic epilepsy & 0.70 & -0.70 \\
& Proposed genetic epilepsy & 1.32 & -1.32 \\
Seizure precipitants & No precipitants & 0.50 & -0.50 \\
& Stress & 1.10 & -1.10 \\
& Sleep & 0.60 & -0.60 \\
& Sleep deprivation & 1.40 & -1.40 \\
MRI brain findings & Normal & 3.30 & -3.30 \\
& Encephalomalacia & 2.10 & -2.10 \\
& Temporal atrophy & 2.20 & -2.20 \\
EEG changes & Normal & 4.10 & -4.10 \\
& Focal changes & 2.50 & -2.50 \\
& Generalized changes & 2.80 & -2.80 \\
\hline
\end{tabular}

quickly [28]. In this study, there was no significant relationship between seizure precipitant and outcome. Some studies suggested that stress increases risk of seizure recurrence $[29,30]$.

In this study, no significant relationship was found between specific anti-epileptic medications used and the outcome. This is consistent with the previous studies which conclude that the majority of AEDs available have demonstrated a similar efficacy for treating epilepsy in elderly [31, 32]. Other studies found that lamotrigine was the most effective AED as measured by 12 -month retention and seizure freedom, with levetiracetam a close second. Oxcarbazepine was consistently less effective than most other AEDs [33]. In this study, there was a significant relationship between MRI findings and outcome, normal MRI brain was significantly associated with good outcome while both encephalomalacia and medial temporal pathology were significantly associated with poor outcome. This is consistent with the previous reports that presence of symptomatic etiology for epilepsy has a poor predictive value for seizure control; this is especially true for stroke in elderly as mentioned before. Analysis of 550 patients with localization-related epilepsy in Glasgow also reported worse remission rates in patient with hippocampal sclerosis than in focal epilepsies due to other causes [34].

In this study, there was a significant relationship between EEG finding (focal and generalized, slowing, or epileptiform discharge) and poor outcome. This is typically consistent with findings of Kim and colleagues in elderly population who stated that epileptiform activity on an EEG was a risk factor for recurrent seizure; this and non-specific abnormality on EEG were the main risk

Table 7 Laboratory predictors of outcome in the studied subjects

\begin{tabular}{|c|c|c|c|}
\hline Variables & Good outcome & Poor outcome & $P$ value \\
\hline Hemoglobin (mean) gm/dl & $12.56 \pm 1.65$ & $12.08 \pm 1.82$ & 0.211 \\
\hline Platelets (mean) $\times 10^{9} / \mathrm{L}$ & $328.05 \pm 91.53$ & $328.83 \pm 97.40$ & 0.972 \\
\hline $\mathrm{Na}$ (mean) $\mathrm{mEq} / \mathrm{L}$ & $139.74 \pm 2.85$ & $139.13 \pm 4.16$ & 0.423 \\
\hline $\mathrm{K}$ (mean) $\mathrm{mEq} / \mathrm{L}$ & $4.05 \pm 0.40$ & $4.07 \pm 0.43$ & 0.845 \\
\hline $\mathrm{Ca}$ (mean) mEq/L & $9.96 \pm 0.59$ & $9.46 \pm 1.19$ & $0.010^{*}$ \\
\hline $\mathrm{Mg}$ (mean) $\mathrm{mEq} / \mathrm{L}$ & $2.04 \pm 0.14$ & $1.97 \pm 0.21$ & $0.046^{*}$ \\
\hline ALT (mean) IU/L & $23.33 \pm 21.63$ & $30.78 \pm 19.03$ & 0.140 \\
\hline AST (mean) IU/L & $25.86 \pm 27.60$ & $40.00 \pm 53.36$ & 0.093 \\
\hline Random blood sugar (mean) mg/dl & $126.30 \pm 43.93$ & $133.39 \pm 48.53$ & 0.509 \\
\hline Creatinine (mean) mg/dl & $0.94 \pm 0.27$ & $0.93 \pm 0.34$ & 0.820 \\
\hline BUN (mean) mg/dl & $35.14 \pm 12.78$ & $31.57 \pm 13.14$ & 0.245 \\
\hline
\end{tabular}

Na sodium, $K$ potassium, $\mathrm{Ca}$ calcium, $M g$ magnesium, ALT alanine transferase, AST aspartate transferase, BUN blood urea nitrogen 
factors of recurrent seizure [35]. On the other hand, study by Lindsten and colleagues have not found EEG to be independently predictive of outcome after adjusting for other factors. They concluded that the prognostic value of routine interictal EEG examination has not been established [14]. In our opinion, an EEG performed soon after a seizure is more likely to detect such abnormalities and is likely to have greater prognostic value.

In this study, there was no significant relationship between laboratory abnormalities and outcome except for low serum $\mathrm{Ca}$ and low serum $\mathrm{Mg}$ which were associated with worse control of seizures. A study by Ushakiran and colleagues found definite association between serum calcium levels and the occurrence of febrile seizures in children. Although serum calcium levels were not in the hypocalcemic range, they were decreased enough to cause a statistical significance in precipitating febrile seizures [36]. This finding was not studied in elderly before to best of our knowledge. Low serum $\mathrm{Mg}$ was also reported as a risk factor for febrile convulsions in children in a number of studies [37, 38] but also not studied in elderly population before.

Strengths of this study include being the first study to address the predictive factors of epilepsy outcome in elderly Egyptian population to the best of our knowledge, also; the prospective design of the study which allowed us to truly identify acute seizures as well as epileptic and non-epileptic events and to classify the seizure type and etiology according to the ILAE recommendations.

The study has some limitations which warrant mention. First, despite the size of the overall sample, there were small numbers in some subgroups as patients with certain illness in past medical history or patients on certain anti-epileptic drugs, which limited the statistical power for these analyses. Second, the study included elderly patients with seizures of any age of onset not just whom seizures started after age of 50; this group may have different outcome. Third, the relative short followup period (6 months) may not be enough to address the natural history of epilepsy in this population and longer periods of follow-up may be needed. There is a need for this study to be conducted with a larger number of participants and in multiple centers of epilepsy in Egypt, longer periods of follow-up may give a more accurate assessment of outcome of epilepsy in this population. A study including patients with seizure onset after age of 50 may be needed and results to be compared to those of this study. Also, there is a need for further studies investigating the role of low serum $\mathrm{Ca}$ and $\mathrm{Mg}$ in control of seizures in elderly population. Finally, there is a need for more studies assessing different aspects of epilepsy in elderly in Egyptian population.

\section{Conclusion}

We conclude from this study that aged Egyptian epileptic population can be predicted to have good or poor outcome of their epilepsy at the start of the treatment according to certain clinical, electrodiagnostic, and laboratory data. This data can guide the use of medical and non-medical treatment of epilepsy in this population.

\section{Acknowledgements \\ Not applicable. \\ Authors' contributions \\ SE collected the data, participated in the sequence alignment, and drafted the manuscript. $\mathrm{MH}$ pioneered the idea of the research and revised the progress step by step. NE, YA, and MM revised the data and participated in its design and coordination. HS performed the statistical analysis. All authors read and approved the final manuscript. \\ Funding \\ Self-financing. \\ Availability of data and materials \\ The datasets used and/or analyzed during the current study are available from the corresponding author on reasonable request.}

\section{Declarations}

Ethics approval and consent to participate

The procedures followed were in accordance with the ethical standards of the responsible committee on human experimentation and with the principles of Helsinki Declaration. Written informed consent was obtained from all participants, and ethical committee permission from Faculty of Medicine Ain Shams University ethical committee (FWA000017585) in August 2019.

Consent for publication

Not applicable.

Competing interests

The authors declare that they have no competing interests.

Received: 16 December 2020 Accepted: 17 March 2021

Published online: 01 April 2021

References

1. Leppik IE. Introduction to the international geriatric epilepsy symposium (IGES). Epilepsy Res. 2006;68(Suppl.1):S1-4.

2. Jayant NA, Vinita JA. Epilepsy in the elderly: special considerations and challenges. Ann Indian Acad Neurol. 2014;17(Suppl.1):S18-26.

3. Stephen LJ, Kelly K, Mohanraj R. Pharmacological outcomes in older people with newly diagnosed epilepsy. Epilepsy Behav. 2006;8(2):434-7. https://doi. org/10.1016/j.yebeh.2005.11.007.

4. Telma A, Aroldo B, Gersonita C, Osvaldo N. Mortality predictors of epilepsy and epileptic seizures among hospitalized elderly. Arq Neuro Psiquiatr. 2015; 73(6):510-5.

5. Telma A, Aroldo B, Gersonita C, Emanoel P, Osvaldo N. Predictors of early seizure recurrence among elderly inpatients admitted to a tertiary center: a prospective cohort study. Epilepsy Behav. 2019;98:145-52.

6. World Medical Association. 1964. Declaration of Helsinki.

7. Fisher RS, Helen CJ, Carol DS. Instruction manual for the ILAE 2017 operational classification of seizure types. Epilepsia. 2017;58(4):522-30. https://doi.org/10.1111/epi.13670.

8. John SD. The promise of new antiepileptic drugs. Br J Clin Pharmacol. 2002; 53(2):123-31.

9. Tomari S, Tomotaka T, Masafumi I, Takayuki M, Fukuma K, Matsubara S, et al. Risk factors for post-stroke seizure recurrence after the first episode. Seizure. 2017;52:22-6. https://doi.org/10.1016/j.seizure.2017.09.007. 
10. MacDonald BK. The prognosis of epilepsy. Seizure. 2001;10(5):347-58. https://doi.org/10.1053/seiz.2000.0523.

11. Hauser WA, Anderson VE, Loewenson RB, McRoberts SM. Seizure recurrence after a first unprovoked seizure. N Engl J Med. 1982;307(9):522-8. https://doi. org/10.1056/NEJM198208263070903.

12. Annegers JF, Shirts SB, Hauser WA, Kurland LT. Risk of recurrence after an initial unprovoked seizure. Epilepsia. 1986;27(1):43-50. https://doi.org/1 0.1111/j.1528-1157.1986.tb03499.x.

13. Stein DG. Progesterone exerts neuroprotective effects after brain injury. Brain Res Rev. 2008;57(2):386-97.

14. Lindsten $\mathrm{H}$, Stenlund H, Forsgren L. Remission of seizures in a populationbased adult cohort with a newly diagnosed unprovoked epileptic seizure. Epilepsia. 2001;42(8):1025-30. https://doi.org/10.1046/j.1528-1157.2001.042 0081025.x.

15. Hitiris N, Mohanraj R, Norrie J, Sills GJ, Brodie MJ. Predictors of pharmaco resistant epilepsy. Epilepsy Res. 2007;75(2-3):192-6. https://doi.org/10.1016/j. eplepsyres.2007.06.003.

16. Reid CA, Jackson GD, Berkovic SF, Petrov S. New therapeutic opportunities in epilepsy: a genetic perspective. Pharmacol Ther. 2010;128(2):274-80 https://doi.org/10.1016/j.pharmthera.2010.07.003.

17. Spalice A, Parisi P, Nicita F, Pizzardi G, Balzo FD, lannetti P. Neuronal migration disorders: clinical, neuroradiologic and genetics aspects. Acta Paediatr. 2009:98(3):421-33. https://doi.org/10.1111/j.1651-2227.2008.01160.x.

18. Sisodiya SM, Marini C. Genetics of antiepileptic drug resistance. Curr Opin Neurol. 2009:22(2):150-6. https://doi.org/10.1097/WCO.0b013e32832923ec.

19. Rizvi S, Lady DL, Lizbeth HR, José F. Epidemiology of early stages of epilepsy: risk of seizure recurrence after a first seizure. Seizure. 2017;49:4653. https://doi.org/10.1016/j.seizure.2017.02.006.

20. Zuberi SM, Joseph DS. Update on diagnosis and management of childhood epilepsies. J Pediatr. 2015;91(Suppl. 1):S67-77. https://doi.org/10.1016/j. jped.2015.07.003.

21. Kanitpong P, Alan G, Kitti L, Pornchai S, Suwanna S. Risk factors of recurrent seizure, co-morbidities, and mortality in new onset seizure in elderly. Seizure. 2013:22(7):577-80.

22. Berg AT, Shinnar S. The risk of seizure recurrence following a first unprovoked seizure: a quantitative review. Neurology. 1991;41(7):965-72. https://doi.org/10.1212/WNL.41.7.965.

23. Lühdorf K, Jensen LK, Plesner AM. Etiology of seizures in the elderly. Epilepsia. 1986;27(4):458-63. https://doi.org/10.1111/j.1528-1157.1986.tb03 567.x.

24. Leone M, Bottacchi E, Beghi E, Morgando E, Mutani R, Cremo R, et al. Risk factors for a first generalized tonic-clonic seizure in adult life. Neurol Sci. 2002;23(3):99-106. https://doi.org/10.1007/s100720200034.

25. Kwan P, Schachter SC, Brodie MJ. Drug-resistant epilepsy. N Engl J Med. 2011;365(10):919-26. https://doi.org/10.1056/NEJMra1004418.

26. Cloyd J, Hauser W, Ramsay R. Epidemiological and medical aspects of epilepsy in the elderly. Epilepsy Res. 2006;68(Suppl.1):S39-48.

27. Al-Mufti F, Claassen J. Neurocritical care: status epilepticus review. Crit Care Clin. 2014;30(4):751-64. https://doi.org/10.1016/j.ccc.2014.06.006.

28. Stasiukyniene V, Pilvinis V, Reingardiene D, Janauskaite L. Epileptic seizures in critically ill patients. Medicina. 2009;45(6):501-7. https://doi.org/10.3390/ medicina45060066.

29. McKee HR, Privitera MD. Stress as a seizure precipitant: identification, associated factors, and treatment options. Seizure. 2017;44:21-6. https://doi. org/10.1016/j.seizure.2016.12.009.

30. Devrimsel HE, Ayten CD, Agah A, Sevim B, Vedat S, Musa O, et al. Exploring psychiatric comorbidities and their effects on quality of life in patients with temporal lobe epilepsy and juvenile myoclonic epilepsy. Psychiatry Clin Neurosci. 2017:71:280-8.

31. Mattson RH, Cramer JA, Collins JF. A comparison of valproate with carbamazepine for the treatment of complex partial seizures and secondarily generalized tonic-clonic seizures in adults. The Department of Veterans Affairs Epilepsy Cooperative Study N ${ }^{\circ} 264$ group. N Engl J Med. 1992;327(11):765-71. https://doi.org/10.1056/NEJM199209103271104.

32. Brodie MJ, Chadwick DW, Anhut H, Otte A, Messmer SL, Maton S, et al. Gabapentin versus lamotrigine monotherapy: a double-blind comparison in newly diagnosed epilepsy. Epilepsia. 2002;43(9):993-1000. https://doi.org/1 0.1046/j.1528-1157.2002.45401.x

33. Arif H, Buchsbaum R, Pierro J, Whalen M, Sims J, Resor SR, et al. Comparative effectiveness of 10 antiepileptic drugs in older adults with epilepsy. Arch Neurol. 2010;67(4):408-15. https://doi.org/10.1001/a rchneurol.2010.49.

34. Stephen $L$, Kwan P, Brodie MJ. Does the cause of localisation-related epilepsy influence the response to antiepileptic drug treatment? Epilepsia. 2001;42(3):357-62. https://doi.org/10.1046/j.1528-1157.2001.29000.x.

35. Kim LJ, Johnson TL, Marson AG, Chadwick DW, MRC MESS study Group. Prediction of risk of recurrence after a single seizure and early epilepsy: further results from the MESS trial. Lancet Neurol. 2006;5(4):317-22. https:// doi.org/10.1016/S1474-4422(06)70383-0.

36. Ushakiran $C B$, Suresh R. Reduced serum calcium is a risk factor for febrile seizures. IJCP. 2017:4(4):1506

37. Baek SJ, Byeon JH, Eun SH, Eun BL, Kim GH. Risk of low serum levels of ionized magnesium in children with febrile seizure. BMC Pediatr. 2018;18(1): 297. https://doi.org/10.1186/s12887-018-1271-z.

38. Chen BB, Kobrzynski M, Campbell C, Filler G. Seizures related to hypomagnesaemia. A case series and review of the literature. Child Neurol Open. 2016;3:2329048X16674834.

\section{Publisher's Note}

Springer Nature remains neutral with regard to jurisdictional claims in published maps and institutional affiliations.

\section{Submit your manuscript to a SpringerOpen ${ }^{\odot}$ journal and benefit from:}

- Convenient online submission

- Rigorous peer review

- Open access: articles freely available online

- High visibility within the field

- Retaining the copyright to your article

Submit your next manuscript at $\boldsymbol{\nabla}$ springeropen.com 